\title{
Hemobilia Due to an Iatrogenic Arteriobiliary Fistula Complicating Laparoscopic Cholecystectomy: A Case Report
}

\author{
Hicham El Bouhaddouti, Khalid Mazine, Abdesslam Bouassria, Ouadii Mouaqit, \\ Elbachir Benjelloun, Abdelmalek Ousadden, Khalid Ait Taleb \\ Department of Visceral Surgery, Faculty of Medicine and Pharmacy of Fez, University Hospital Hassan II-Fes, \\ Sidi Mohamed Ben Abdellah University, Fez, Morocco \\ Email: $\underline{\text { h.elbouhaddouti@yahoo.fr }}$
}

Received 24 April 2014; revised 3 June 2014; accepted 22 June 2014

Copyright @ 2014 by authors and Scientific Research Publishing Inc. This work is licensed under the Creative Commons Attribution International License (CC BY). http://creativecommons.org/licenses/by/4.0/

(c) (;) Open Access

\begin{abstract}
Hemobilia is the result of a pathological communication between bile duct and intra or extrahepatic vessel. $40 \%$ to $60 \%$ of the haemobilia cases are Iatrogenic, and the other causes are either vascular malformations or hepatic blunt trauma. We describe the case history of a patient in which laparoscopic cholecystectomy was complicated 3 months later by massive hemobilia. The cause of haemorrhage was a fistula between the principal bil duct and the right hepatic artery. This complication was successfully managed by surgery and angiographic embolization with full recovery of the patient.
\end{abstract}

\section{Keywords}

Hemobilia, Gastrointestinal Bleeding, Arteriography

\section{Introduction}

Hemobilia is the process of bleeding into the biliary tree and is an unusual cause of upper gastrointestinal hemorrhage. It is only a symptom revealing underlying disease. Blunt hepatic trauma and postsurgical pseudoaneurysms of hepatic arteries are the cause of hemobilia in 10\% of cases [1] [2]. A biliary fistula complicating laparoscopic cholecystectomy is a rare, unpredictable, and life-threatening vascular complication. The pathogenesis of this uncommon but sometimes fatal complication still remains unclear. Mechanical or thermal injuries

How to cite this paper: El Bouhaddouti, H., Mazine, K., Bouassria, A., Mouaqit, O., Benjelloun, E., Ousadden, A. and Taleb, K.A. (2014) Hemobilia Due to an latrogenic Arteriobiliary Fistula Complicating Laparoscopic Cholecystectomy: A Case Report. Open Journal of Gastroenterology, 4, 275-278. http://dx.doi.org/10.4236/ojgas.2014.46040 
have been considered responsible. In more than $80 \%$ of cases, trans-arteriographic embolization is the first definite treatment .We report the case history of a patient in which laparoscopic cholecystectomy was complicated 3 months later by massive hemobilia.

\section{Case Presentation}

A 50-year-old patient, presented to the emergency department 3 months post laparoscopic cholecystectomy with epigastric pain, cholestatic jaundice and multiple episodes of hematemesis. With the exception of recent laparoscopic cholecystectomy, the patient had no significant past medical history. On examination, he was pale; blood pressure was 100/60 $\mathrm{mmHg}$ and heart rate was $98 \mathrm{bpm}$. His hemoglobin $(\mathrm{Hb})$ was at $7 \mathrm{~g} / \mathrm{dl}$ and bilirubin was $78 \mathrm{mg} / \mathrm{l}$. Abdominal percutaneous ultrasound examination showed a dilation of intra- and extrahepatic bile ducts measured $11 \mathrm{~mm}$ without visible obstacle. Emergency upper gastrointestinal endoscopy revealed multiple blood clots over the anterior/superior wall of the first and second parts of the duodenum. Catheterization of the common bile duct showed active hemobilia due to biliary-vascular fistula. The patient presented hemodynamic instability, he underwent an emergency surgery; surgical exploration highlighted several clips of the common bile duct that were removed and an injury of the proper hepatic artery which was sutured with implementation of a Kehr drain in the bile duct. He had a transfusion and his $\mathrm{Hb}$ rose to $10 \mathrm{~g} / \mathrm{dl}$. 7 days after this procedure was performed rebleeding occurred, Kehr drain brought bile mixed with blood. A CT angiography showed an aneurysm of the hepatic artery next to a metal clip with hemobilia. The arteriography (Figure 1) viewed a pseudoaneurysm sized $1.5 \mathrm{~cm}$ sited in the right terminal branch of the proper hepatic artery. Trans-arteriographic embolization was achieved by filling the entire pseudoaneurysm with biological glue. The patient had an uneventful immediate clinical course without rebleeding. A control CT angiography confirmed the disappearance of the pseudoaneurysm (Figure 2). However during a control 3 months later, the patient presented a cholestatic jaundice, biochemical tests demonstrated an important biological cholestasis (bilirubin at $100 \mathrm{mg} / \mathrm{l}$ ). Abdominal ultrasonography showed dilated intra and extrahepatic biliary tract. Bili MRI showed presence of glue in the bile duct responsible of an important bile duct dilatation upstream. Therefore a surgical option was chosen, and a biliary-jejunal anastomosis was executed. The recovery was uneventful with normalization of laboratory tests and a normal follow-up CT scan. 1 year after surgery, the patient is well and is complaint free.

\section{Discussion}

Hemobilia is a rare entity. It is classically associated with Quincke's triad of biliary colic, jaundice, and gastrointestinal bleeding; however, the complete triad is reported in less than $40 \%$ of patients [2] [3]. A significant

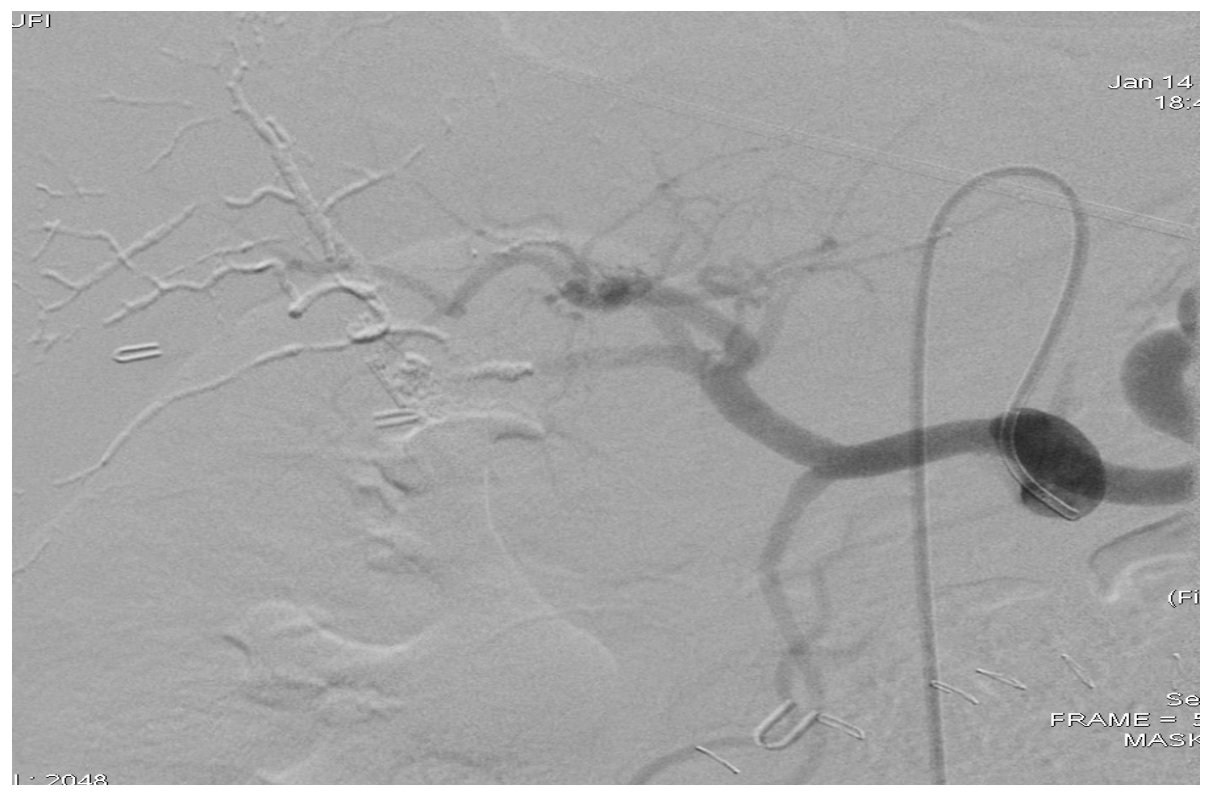

Figure 1. Arteriography of the hepatic artery, embolization of pseudoaneurism. 


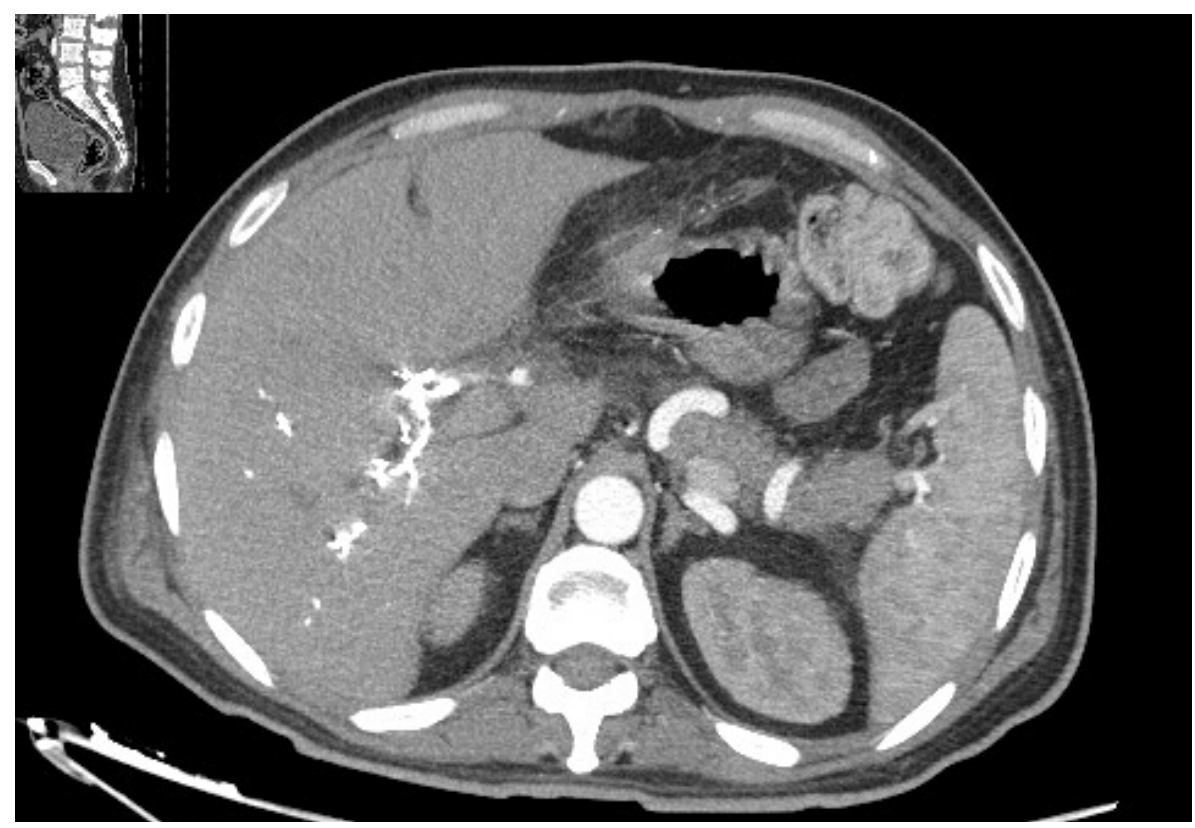

Figure 2. Angioscan after embolization of the pseudoaneurism, no contrast product extravasation.

majority of cases arise from iatrogenic causes such as, hepatobiliary procedures and, less commonly, laparoscopic cholecystectomy [4]. Noniatrogenic causes include blunt abdominal trauma, localized infection, gallstones, and hepatic tumors; it can also be secondary to a vascular abnormality which is most often a hepatic artery aneurysm [4]. Although laparoscopic cholecystectomy is the treatment of choice for symptomatic cholelithiasis, the incidence of biliary and vascular injuries is increased by this procedure. Most arterial complications occur secondary to direct injury or diathermy heat transmitted via surgical clips [4]. The mechanism of hepatic or cystic artery pseudoaneurysms post cholecystectomy is unclear but likely involves direct vascular injury, thermal injury, erosion due to clip intrusion, which is the case with our patiente, bile leakage, and infection .The primary lesion is an intrahepatic communication between vessels and bile ducts, more often arterial than portal.

In our patient case, signs found were a cholestatic jaundice and hematemesis. There are early biological signs of hepatocellular suffering such as elevated c-glutamyltransferase, alkaline phosphatase, transaminases and direct bilirubin. Gastroduodenal endoscopy has a great diagnostic value when it shows the blood from the ampulla of Vater [4]. Angiography has a significant place both for the positive and topographic diagnosis. Because of anatomical variations, the two arterial roads, celiac and mesenteric must be explored. The classic image of contrast passage into the biliary tract is rare, a pseudoaneurysm is often objectified [5] [6].

In our case the diagnosis was made by Endoscopic retrograde cholangio pancréatographie (ERCP) and CT angiography. The treatment of choice is radiological embolization by metal coils or glue whose efficiency varies between $80 \%$ and $100 \%$. In Addition this radiological procedure carries with serious risks such as hepatobiliary necrosis, hepatocellular insufficiency, bleeding, abscess formation and gallbladder fibrosis [7] [8]. With these risks, early surgical intervention following failed radiologic intervention for hemobilia is often suggested [9]. A selective arterial ligation is usually recommended.

In our case, surgery did not get the disconnection of the arterio-biliary fistula; Arterial embolisation with glue was the efficient treatment that allowed hemostasis. Unfortunately, the complication encountered was a cholestatic jaundice with dilated biliary intra and extrahepatic tract due to a glue passage in the biliary ducts. This complication was surgically treated by biliodigestive bypass.

\section{Conclusion}

Gastrointestinal bleeding after a cholecystectomy may be a sign of haemobilia. The diagnosis is confirmed by duodenoscopy. The angioscan can find the site of the fistula between the bile duct and the artery that is injured. We discovered that metal clips can be a cause of these injuries when they are misplaced. This happens when 
there are difficulties in bleeding control.

\section{References}

[1] Echarrab, M., Medarheri, J., Elounani, M., Louchi, A., Balafrej, S., Amraoui, M., Errougani, A., Benchekroun, A. and Chkoff, R. (2000) Hemobilia: Which Treatement? about an Observation, and Literature Review. Medecine du Maghreb.

[2] Sansonna, F., Boati, S., Sguinzi, R., Migliorisi, C., Pugliese, F. and Pugliese, R. (2011) Severe Hemobilia from Hepatic Artery Pseudoanevrysm. Case Rep Gastrointest Med, 2011, Article Number: 925142.

[3] Petrou, A., Brennan, N., Soonawalla, Z. and Anthony Silva, M. (2012) Hemobilia Due to Cystic Artery Stump Pseudoaneurysm Following Laparoscopic Cholecystectomy: Case Presentation and Literature Review. United Kingdom Int Surg, 97, 140-144.

[4] Green, M.H.A., Johnson, C.D. and Jamieson, N.V. (2001) Haemobilia. British Journal of Surgery, 88, 773-786. http://dx.doi.org/10.1046/j.1365-2168.2001.01756.x

[5] Peters, J.H., Ellison, E.C., Innes, J.T., Liss, J.L., Nichols, K.E., Lomano, J.M., et al. (1991) Safety and Efficacy of Laparoscopic Cholecystectomy: A Prospectiveanalysis of 100 Initial Patients. Annals of Surgery, 213, 3-12. http://dx.doi.org/10.1097/00000658-199101000-00002

[6] Madanur, M.A., Battula, N., Sethi, H., Deshpande, R., Heaton, N. and Rela, M. (2007) Pseudoaneurysm Following Laparoscopic Cholecystectomy. Hepatobiliary \& Pancreatic Diseases International, 6, 294-298.

[7] England, R.E., Marsh, P.J., Ashleigh, R. and Martin, D.F. (1998) Pseudoaneurysm of the Cystic Artery: A Rare Cause of Hemobilia. Clinical Radiology, 53, 72-75. http://dx.doi.org/10.1016/S0009-9260(98)80041-X

[8] Maurel, J., Aouad, K., Martel, B., Segol, P. and Gignoux, M. (1994) Traumatic Hemobilia. Witch Treatment? A Cae Report. Annales de Chirurgie, 48, 572-575.

[9] Mangiante, E.C., Pritchard, E. and Fabian, T.C. (1998) Traumatic Hemobilia: Aetiology, Diagnosis and Management (Clinical Conference). J. Tenu. Med. Asoc, 81, 575-577. 
Scientific Research Publishing (SCIRP) is one of the largest Open Access journal publishers. It is currently publishing more than 200 open access, online, peer-reviewed journals covering a wide range of academic disciplines. SCIRP serves the worldwide academic communities and contributes to the progress and application of science with its publication.

Other selected journals from SCIRP are listed as below. Submit your manuscript to us via either submit@scirp.org or Online Submission Portal.
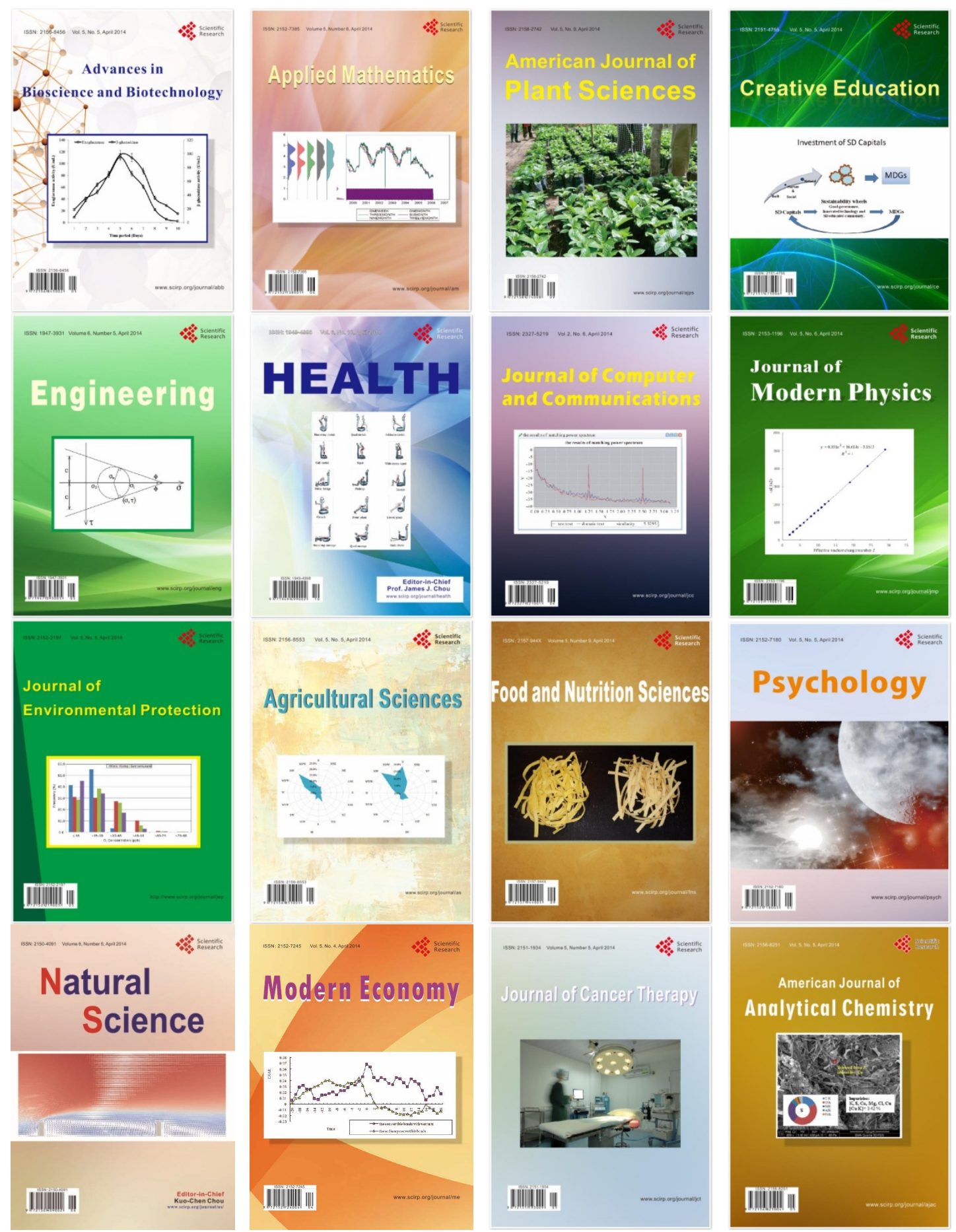